\title{
Parenting style as a predictor of dietary score change in children from 4 to 14 years of age. Findings from the Longitudinal Study of Australian Children
}

\author{
Alissa J Burnett 1 ** $\odot$, Karen E Lamb ${ }^{1,2,3,4}$, Alison C Spence ${ }^{1}$, Kathleen E Lacy ${ }^{1}$ and \\ Anthony Worsley ${ }^{\top}$ \\ 'Institute for Physical Activity and Nutrition, School of Exercise and Nutrition Sciences, Deakin University, \\ 221 Burwood Highway, Geelong, Burwood, VIC 3125 , Australia: ${ }^{2}$ Murdoch Children's Research Institute, \\ Royal Melbourne Hospital, Parkville, VIC, Australia: ${ }^{3}$ Department of Paediatrics, University of Melbourne, \\ Parkville, VIC, Australia: ${ }^{4}$ Centre for Epidemiology and Biostatistics, Melbourne School of Population and Global \\ Health, University of Melbourne, Parkville, VIC, Australia
}

Submitted 10 November 2020: Final revision received 25 May 2021: Accepted 13 July 2021: First published online 23 July 2021

\begin{abstract}
Objective: To examine associations between parenting style and changes in dietary quality score across childhood.

Design: This longitudinal analysis included the child's frequency of consumption for twelve food and drink items reported by mothers of children (aged 4-8 years) and children (aged 10-14 years) during face-to-face interviews biennially. These items were combined into dietary scores based on the Australian Dietary Guidelines. Parenting styles were classified at baseline as authoritative, authoritarian, permissive and disengaged. Multilevel modelling was used to examine changes in diet quality score over time by maternal parenting styles.

Setting: The Longitudinal Study of Australian Children.

Participants: A total of 4282 children aged 4 to 14 years.

Results: Children's diet quality score declined over time between 4 and 14 years of age $(\beta=-0 \cdot 10,95 \% \mathrm{CI}(-0 \cdot 11,-0 \cdot 08))$. There was strong evidence to suggest that change in diet quality differed dependent on baseline maternal parenting style, although diet quality declined for all groups. Children with authoritative mothers had the greatest decline in diet quality score over time $(\beta=-0 \cdot 13 ; 95 \%$ CI $(-0 \cdot 18,-0 \cdot 08))$, while children with disengaged mothers had the lowest decline $(\beta=-0.03 ; 95 \% \mathrm{CI}(-0 \cdot 07,0 \cdot 01))$. However, it is important to note that children with authoritative mothers had a better dietary quality score than children of permissive or disengaged mothers for most of their childhood.

Conclusion: These findings question the previous assumptions that early exposure to an authoritative parenting style has lasting positive effects on the dietary intake of children.
\end{abstract}

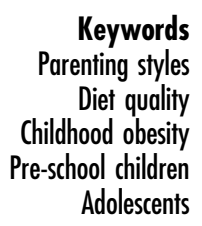

The prevalence of childhood overweight and obesity is a significant public health issue ${ }^{(1-3)}$. In Australia, one in four children aged 2 to 5 years are reported to be overweight or obese $^{(4)}$, with a similar rate for children aged $5-18$ years ${ }^{(5)}$. This is concerning as children who are overweight are at higher risk of overweight or obesity as adolescents and adults ${ }^{(6)}$. Obesity is associated with a number of chronic diseases, including CVD, cancer and diabetes mellitus $^{(1,7-9)}$.

The causes of overweight and obesity in childhood are complex; however, poor diet quality is one of the main contributing factors ${ }^{(3,10)}$. For example, more than one-third of Australian children's daily energy intake comes from energy-dense, nutrient-poor foods and beverages such as snack foods, confectionery and sugar sweetened beverages, and most children are generally not meeting their recommended daily serves of vegetables ${ }^{(4)}$. Understanding factors that influence children's dietary intake in early years could facilitate the development of interventions to improve diet across childhood. Parents are one of the main influences on the dietary intake of children, with mothers being of significant importance as they generally spend 
more time with their children and undertake more of the food provision than fathers ${ }^{(11,12)}$.

The influence a mother has over her child's dietary intake is thought to be strongest in early childhood ${ }^{(13-16)}$, which is important as habits formed in early childhood are likely to track into adolescence when greater independence and autonomy over food choices are developed ${ }^{(17)}$. The increase in independence that a child has during adolescence and a busier lifestyle can lead to greater reliance on convenience foods ${ }^{(18)}$. Previous research has suggested that the transition to secondary school is associated with increased consumption of unhealthy foods and a decrease in consumption of fruit and vegetables ${ }^{(17)}$. Less than $3 \%$ of Australians aged 12-18 years consume the recommended five portions of vegetables/d and about three out of five consume the recommended two portions of fruit ${ }^{(5,19)}$.

Maternal parenting styles in early childhood may be an important determinant of the quality of a child's diet across childhood, as parenting styles are assumed to be stable ${ }^{(20)}$, with only one study which examined their stability in parents of adolescents showing they are stable ${ }^{(21)}$. Parenting styles are defined as parenting behaviours and practices which influence the development of a child and are a part of the broader parenting environment ${ }^{(22,23)}$. The four commonly recognised parenting styles, based on two dimensions, are authoritative (high control/high warmth), authoritarian (high control/low warmth), permissive (low control/high warmth) and disengaged (low control/low warmth) ${ }^{(24)}$. Understanding the influence of parenting styles on the dietary intake of children will inform future interventions by identifying groups of parents who may need additional support in promoting healthy eating behaviours for their children.

In cross-sectional studies, parenting styles have been found to be associated with the dietary intakes of pre-school children aged $1.5-5$ years $^{(11,25-27)}$ as well as older children (5-18 years) $^{(28-30)}$. The literature shows that children with authoritative parents had higher intakes of fruits and vegetables ${ }^{(11,25-30)}$ and lower intakes of unhealthy snack foods ${ }^{(30)}$. However, findings are inconsistent; one study examining parenting styles and dietary quality in older children (8-12 years) did not find an association $^{(31)}$. Notably, the samples in these studies were relatively small (all less than 400) and only one study, from Australia, was nationally representative ${ }^{(26)}$. Furthermore, these studies were all cross-sectional which prohibits changes in outcomes to be examined.

Although associations between parenting styles and intakes of individual foods have been reported previously, to our knowledge, no studies have examined the associations between parenting styles and dietary quality in pre-school children. It is important to consider a child's comprehensive dietary consumption (known as dietary scores or diet quality) as people do not consume individual foods in isolation ${ }^{(32)}$. Diet quality scores including multiple food groups are important as they retain the complexity of foods and diets without reducing the assessment to a single nutrient or food item; they are increasingly recognised as important predictors of non-communicable diseases ${ }^{(33)}$.

To date, no studies have examined associations between parenting style and diet quality in a longitudinal sample tracking from early childhood to early adolescence. Therefore, this study aims to examine associations between maternal parenting styles in early childhood, when a mother is likely to have the most influence over her child's dietary intake, and change in diet quality score from early childhood into early adolescence in a large nationally representative sample of Australian children aged 4 to 14 years.

\section{Methods}

\section{Study design and sample}

This study used data from the Longitudinal Study of Australian Children (LSAC). The LSAC collected data from two cohorts biennially from 2004; the infant cohort (aged 0-1 years at baseline) and the child cohort (aged 4-5 years at baseline). The full methodology of the LSAC is described elsewhere ${ }^{(34)}$. Briefly, participants were randomly selected from the Health Insurance Commission Medicare database in which most Australians are represented. Medicare is Australia's universal healthcare scheme.

The data for the LSAC were collected primarily from the children's parents (usually the mother, known as Parent 1 ), with additional data provided by other caregivers (e.g. Parent 2, usually the father) and the children themselves (beginning when children were 10 years of age for only some questions, including the dietary questions). Data were collected using both face-to-face interviews and interviewer-assisted questionnaires for primary carers and written questionnaires for the secondary carer.

Of the 18800 families that were invited to participate in the LSAC, 10090 (54\%) agreed to take part, with 4983 children in the child cohort at baseline (the remainder were in the infant cohort) ${ }^{(34)}$. The present longitudinal study involves data from all six waves of the child cohort available at the time of analysis (i.e. to the age of $14-15$ years), as the focus was on examining changes in dietary intake of children over time through to adolescence. The infant cohort was therefore omitted as it does not yet have adolescent data available at this time.

\section{Outcome measures}

The LSAC collected data on the consumption of twelve food and drink items during face-to-face interviews including raw and cooked vegetables, fruit, water, full-cream and skimmed milk products, hot takeaway foods, hot takeaway snacks, savoury snacks, sweet snacks, soft drinks and energy drinks (outlined in Table 1). The questions were from the Amherst Health and Activity Study ${ }^{(35)}$ and have 
Table 1 Derivation of the dietary score from the LSAC dietary questions

\begin{tabular}{|c|c|c|}
\hline Categories & Food included in category & $\begin{array}{l}\text { Points allocation (range for each } \\
\text { category: } 0-2 \text { ) }\end{array}$ \\
\hline Fruit (1 question) & - Fresh fruit & $\begin{array}{l}0: \text { 'not at all' } \\
\text { 1: 'once' } \\
\text { 2: 'more than once' }\end{array}$ \\
\hline Vegetables (2 questions) & $\begin{array}{l}\text { - Cooked vegetables } \\
\text { - Raw vegetables }\end{array}$ & $\begin{array}{l}0: \text { 'not at all' for both questions } \\
\text { 1: 'once' for either question } \\
\text { 2: responses that equate to a } \\
\text { frequency of 'more than once' }\end{array}$ \\
\hline Water (1 question) & - Water & $\begin{array}{l}0: \text { 'not at all' } \\
\text { 1: 'once' } \\
\text { 2: 'more than once' }\end{array}$ \\
\hline Milk products or alternatives (2 questions) & $\begin{array}{l}\text { - Full-cream milk/full-cream milk products } \\
\text { - Skimmed milk/skimmed milk products or } \\
\text { soya milk/soya milk products }\end{array}$ & $\begin{array}{l}0: \text { 'not at all' for both questions } \\
\text { 1: 'once' for either question } \\
\text { 2: responses that equate to a } \\
\text { frequency of 'more than once' }\end{array}$ \\
\hline Fatty foods (3 questions) & $\begin{array}{l}\text { - Meat pie, hamburger, hot dog, sausage } \\
\text { or sausage roll } \\
\text { - Hot chips or French fries } \\
\text { - Potato chips or savoury snacks such as } \\
\text { Twisties }\end{array}$ & $\begin{array}{l}\text { 2: 'not at all' for all questions } \\
\text { 1: 'once' for one question } \\
\text { 0: responses that equate to a } \\
\text { frequency of 'more than once' }\end{array}$ \\
\hline Sugary foods (1 question) & - Biscuits, doughnuts, cake, pie or chocolate & $\begin{array}{l}\text { 2: 'not at all' } \\
\text { 1: 'once' } \\
\text { 0: 'more than once' }\end{array}$ \\
\hline $\begin{array}{l}\text { Sugar-sweetened beverages ( } 1 \text { question for } \\
\text { waves } 1-5,2 \text { questions for wave } 6 \text { ) }\end{array}$ & $\begin{array}{l}\text { - Non-diet soft drink or cordial (waves 1-6) } \\
\text { - Energy drinks, for example, Redbull, } \\
\text { Mother or V (wave 6) }\end{array}$ & $\begin{array}{l}\text { Waves } 1-5 \\
\text { 2: 'not at all' } \\
\text { 1: 'once' } \\
0: \text { 'more than once' } \\
\text { Wave } 6 \\
\text { 2: 'not at all' for both questions } \\
\text { 1: 'once' for either question } \\
0: \text { responses that equate to a } \\
\quad \text { frequency of 'more than once' }\end{array}$ \\
\hline
\end{tabular}

The question asked of the parents was: 'In the last $24 \mathrm{~h}$ has your child had the following foods and drinks once, more than once, or not at all?'. The question repeatedly asked of the child was 'Thinking about yesterday, how often did you have... [fresh fruit].?'.

not been validated previously. The primary parent was asked to report the frequency of their child's food and drink consumption in the $24 \mathrm{~h}$ prior to the interview at 4,6 , and 8 years of age. The children reported their own consumption at 10, 12, and 14 years of age. The question asked of the parents was: 'in the last $24 \mathrm{~b}$ has your child had the following foods and drinks once, more than once, or not at all?'. Questions asked of the child included thinking about yesterday, how often did you have takeaway foods including meat pie, hamburger, hot dog, sausage or sausage roll?', with a separate question asked for each food or drink and response options of once, more than once, or not at all.

This study used a derived dietary score for each wave, as previously adopted elsewhere ${ }^{(36)}$; details of the derivation of the dietary score are described in Table 1. Briefly, the dietary score is based on food group alignment with the Australian Dietary Guidelines ${ }^{(37)}$. The twelve food and drink items were collapsed into seven categories of foods and drinks, which were each allocated a score and then summed together. Fruit, vegetables, water and milk products or alternatives were positively scored (i.e. highest consumption scored 2 and lowest consumption scored 0 ), whereas fatty foods, sugary foods and sugar-sweetened beverages were reverse scored (i.e. highest consumption scored 0 and lowest consumption scored 2). The possible range of dietary scores was therefore from 0 to 14 , with 14 representing the healthiest score. A similar method has shown to be a valid and reliable tool to assess dietary quality $^{(38)}$.

\section{Exposure measures}

Parenting styles were assessed based on two parenting dimensions: warmth and control ${ }^{(39)}$. A written questionnaire was self-completed by parents during face-to-face interviews at baseline (children aged 4 years); the interviewers were present to assist the completion of the questionnaire if needed. The questionnaire contained 11 questions pertaining to parenting behaviours. Responses were recorded on five-point Likert scales ranging from 1 (never/almost never) to 5 (all the time). The warmth parenting dimension was assessed by averaging the scores of the six items from the Child Rearing Questionnaire ${ }^{(40)}$, which included items such as 'How often do you have warm, close times together with this child?'. The control parenting dimension was assessed by averaging the scores of the five items from the Canadian National Longitudinal Survey of Children and Youth, which included items such as 'When you discipline this child, how often does he/she ignore the punishment?' (three questions were reverse scored) ${ }^{(41)}$. 
This is an accepted method of assessing parenting styles that is consistent with previous literature ${ }^{(11,26,42)}$. Each parenting dimension has previously demonstrated good reliability and internal consistency in the same sample $(r=0.73-0.83)$, as well as good validity when modelled against a variety of coexisting family and parental characteristics in previous studies in Australia ${ }^{(43,44)}$.

The warmth and control parenting dimension scores were dichotomised and combined into four categorical parenting styles: authoritative, authoritarian, permissive and disengaged, as per Wake et al. ${ }^{(44)}$. Following this approach, as the warmth and control scales were both shown to be positively skewed and there are no standard cut points for these scales, the scores were dichotomised at the least positive tertile. Scores that fell above the 33rd percentile were classified as high warmth and/or high control, while scores that fell below the 33rd percentile were considered low warmth and/or low control. The combination of high warmth and high control was classified as authoritative; low warmth and high control as authoritarian; high warmth and low control as permissive; and low warmth and low control as disengaged. This study focused on the parenting styles from baseline (i.e. child aged 4 years) of mothers who were the primary caregiver of their child; $2 \%(n 77)$ of participants reported someone other than the mother as the primary caregiver and were excluded from this analysis.

Parenting styles at the age of 14 years were considered in a sensitivity analysis to assess if the estimated associations were consistent when only including parents who had the same parenting style at 4 and 14 years of age. The same cut points used at baseline were used at wave 6 .

\section{Potential confounders}

Potential confounders, which were considered likely to be related to exposure and outcome, based on previous literature ${ }^{(25,42,45,46)}$, included maternal age, child sex, number of children in the household $(0,1,2$ or $3+)$, maternal country of birth (Australia/not Australia), maternal education level (less than year 12, year 12, trade/certificate or tertiary) and parenting arrangements (1 or 2 parent home). Maternal education was used as an indicator of socio-economic status, as many people within the LSAC sample did not report their income (12\%), and previous research suggests that education status is a reliable indicator of socio-economic status ${ }^{(47)}$. All confounders were measured at baseline.

\section{Statistical analysis}

The statistical analyses were conducted using Stata 15 (Stata Corp.) $)^{(48)}$. Multilevel modelling was used to examine change in diet quality score over time (six waves) by maternal parenting style, accounting for the nesting of study waves within participants. Participants had to have complete data for all study variables (parenting styles, diet quality score and confounders) at baseline and have diet quality score measured in at least one of the subsequent waves (waves 2-6) to be included in the analysis (since multilevel models permit subjects with missing outcome data at some of the time points $\left.{ }^{(49)}\right)$. Of the 4983 children who participated at baseline, 4570 had complete data at baseline, and 4282 (86\%) also had at least one further wave of dietary data to enable inclusion in the longitudinal analysis (Fig. 1). Missing diet quality and confounder data at baseline were assumed to be missing completely at random, as the baseline characteristics for the full sample were compared to those in the complete case sample.

A multilevel linear regression model, with both a random intercept and random slope for time, was used to model the outcome measure (child's diet quality score) by wave (model 1) to determine if diet quality score changed over time for all participants from early childhood (wave 1) to adolescence (wave 6). Likelihood ratio tests were used to determine if the model fit improved by including a random intercept in addition to a random slope. The random coefficient for time allows for random variability in the change in dietary score over time for each individual. To assess whether change in diet quality score over time differed dependent on maternal parenting style, an interaction between maternal parenting style and time was included in the model, in addition to the main effect of maternal parenting style (model 2). To examine whether there was evidence of an interaction after accounting for other covariates, potential confounding variables were included (model 3). As per previous studies, disengaged parenting style was considered as the reference category for models 2 and $3^{(11,26,42)}$.

To interpret the interaction effects, a post hoc analysis was conducted (margins test) to estimate the change in diet quality score over time for each of the four maternal parenting styles.

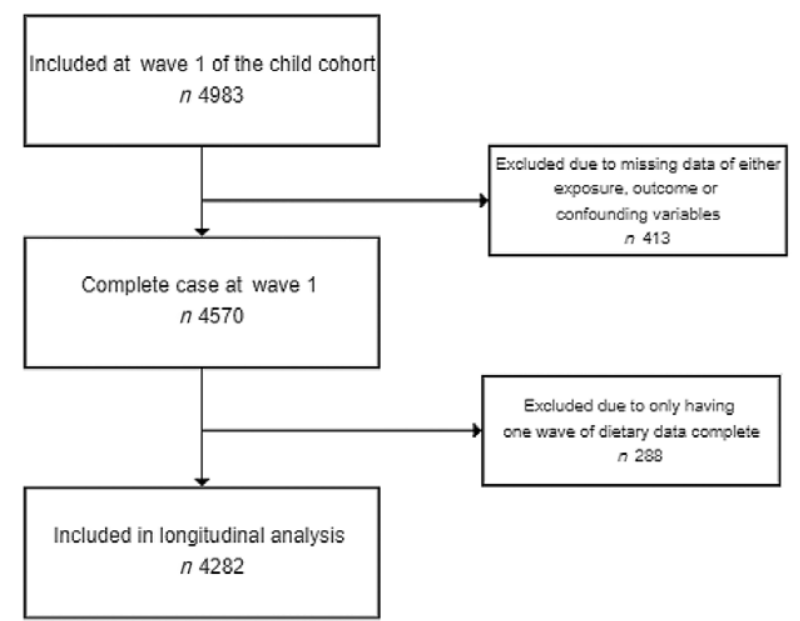

Fig. 1 Flow chart of included participants from wave 1 (baseline) of the child cohort of the LSAC 
To examine the associations between parents who had the same parenting style at 4 and 14 years of age and change in child dietary quality score over time, a sensitivity analysis was conducted. Of the 3559 participants included in the study at wave 6, 3043 had complete data; 1370 (45\%) were included in the sensitivity analysis, as these were mothers with the same parenting style at 4 and 14 years of age. This was conducted using the same multilevel linear regression models and post hoc analysis.

\section{Results}

Table 2 shows the baseline characteristics of the total sample. Just over half of the children were male (50.7\%), and the mean age of the children at baseline was 4.2 years and at wave 6 it was 14.4 years. The mean age of the mothers at baseline was 34.6 years $(\mathrm{SD}=5 \cdot 3)$. Of the 4570 participants included in the study at baseline, $36 \%$ of mothers were classified as having an authoritative parenting style, $27 \%$ authoritarian, $18 \%$ permissive and $19 \%$ disengaged. The average diet quality score for all children at baseline was $9 \cdot 79(\mathrm{SD}=2 \cdot 22)$, and the average diet quality score at age 14 years was $9.65(\mathrm{SD}=2 \cdot 34)$.

Model 1 showed that child diet quality score declined on average over time between 4 and 14 years of age $(-0 \cdot 10,95 \% \mathrm{CI}(-0 \cdot 11,-0 \cdot 08))$. The estimates of subsequent models ( 2 and 3 ) from the multilevel models are presented

Table 2 Demographic and parenting style characteristics of the LSAC child cohort at baseline ( $n$ 4570)

\begin{tabular}{|c|c|c|}
\hline Variable & $n(\%)$ or mean & SD \\
\hline \multicolumn{3}{|l|}{ Child's sex } \\
\hline Male & 2315 & $50 \cdot 7$ \\
\hline Female & 2255 & $49 \cdot 3$ \\
\hline Child's age (years) & $4 \cdot 17$ & 0.38 \\
\hline \multicolumn{3}{|l|}{ Household type } \\
\hline Two-parent household & 3964 & $86 \cdot 7$ \\
\hline Single-parent household & 606 & 13.3 \\
\hline \multicolumn{3}{|c|}{ Number of children in the home } \\
\hline 1 child & 507 & $11 \cdot 1$ \\
\hline 2 children & 2240 & $49 \cdot 0$ \\
\hline 3 or more children & 1823 & 39.9 \\
\hline \multicolumn{3}{|l|}{ Mother's country of birth } \\
\hline Born in Australia & 3541 & 77.5 \\
\hline Born overseas & 1029 & 22.5 \\
\hline \multicolumn{3}{|l|}{ Mother's education level } \\
\hline Less than year 12 & 1008 & $22 \cdot 1$ \\
\hline Year 12 & 719 & $15 \cdot 7$ \\
\hline Trade/certificate & 1559 & $34 \cdot 1$ \\
\hline Tertiary & 1284 & $28 \cdot 1$ \\
\hline Mother's age (years) & $34 \cdot 60$ & $5 \cdot 32$ \\
\hline \multicolumn{3}{|l|}{ Parenting styles } \\
\hline 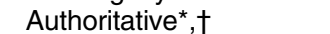 & 1651 & $36 \cdot 1$ \\
\hline Authoritarian†, $\ddagger$ & 1226 & $26 \cdot 8$ \\
\hline Permissive $^{*}, \S$ & 837 & $18 \cdot 3$ \\
\hline Disengaged $\ddagger, \S$ & 856 & $18 \cdot 7$ \\
\hline Diet quality score & 9.79 & 2.22 \\
\hline
\end{tabular}

*Warmth range 4.5-5.0.

†Control range 4.0-5.0.

fWarmth range 2.3-4.3.

§Control range 1.2-3.8. in Table 3. There was evidence that the change in diet quality score over time differed dependent on maternal parenting style $(P<0 \cdot 001)$. Children with authoritative and authoritarian mothers at baseline had the highest diet quality score at baseline. Results showed that the diet quality score appeared to decline over time for all parenting styles. However, the magnitude of decline differed dependent on the parenting style. Findings from the post hoc analysis showed that children with authoritative mothers had the greatest diet quality score decline over time $(-0.13 ; 95 \% \mathrm{CI}(-0 \cdot 18,-0 \cdot 08))$, while children of authoritarian $(-0.04 ; 95 \%$ CI $(-0.09,0.01))$, permissive $(-0.06 ; 95 \%$ CI $(-0.11,0.00))$ and disengaged mothers $(-0.03 ; 95 \%$ CI $(-0.07,0.01))$ showed less decline over time. However, children of authoritative and authoritarian mothers had a better dietary quality score than children of permissive or disengaged mothers for most of their childhood. These findings are illustrated in Fig. 2.

Sensitivity analysis showed similar associations. Findings from the post hoc analysis showed that children with authoritative mothers had the greatest diet quality score decline over time $(-0.13 ; 95 \%$ CI $(-0 \cdot 21,-0 \cdot 05))$, while children of authoritarian $(-0.05 ; 95 \%$ CI $(-0.13$, $0 \cdot 02)$, permissive $(-0 \cdot 10 ; 95 \% \mathrm{CI}(-0.23,0 \cdot 02))$ and disengaged mothers $(-0.02 ; 95 \%$ CI $(-0.08,0.04))$ showed less decline over time (see online Supplemental Table 1).

\section{Discussion}

This is the first study to examine associations between maternal parenting styles in early childhood and changes in diet quality score across childhood. The study found a small decline in average diet quality score amongst a nationally representative sample of children from 4 to 14 years of age. The study also found that children of the authoritative parenting style had the greatest decline in diet quality score. Previous studies have found that the percentages of children consuming fruit and vegetables decline significantly as they move into adolescence, while sugarsweetened beverage and unhealthy snack consumption increase over this time ${ }^{(17,50-52)}$. These negative dietary changes are similar to the current findings as diet quality score declined, though the decline was quite small. The overall average decline in diet quality score was estimated to be one-tenth of a unit per 2 years. A one-point decrease in diet quality score equated to a decrease of one frequency of fruit or vegetables (e.g. reporting they had vegetables once or more than once in the past $24 \mathrm{~h}$ ) or an increase by one frequency of fatty foods, sugary foods or sugarsweetened beverages per $\mathrm{d}$.

The results presented in the current study question the previous assumptions that early exposure to an authoritative parenting style has lasting positive effects. Children of authoritative mothers started with a higher diet quality score than those with permissive or disengaged mothers 
Diet score change from 4 to 14 years by parenting style

6063

Table 3 Multilevel models of associations between parenting styles and diet quality score over 10 years (2004-2014) in the LSAC child cohort ( $n$ 4282)

\begin{tabular}{|c|c|c|c|c|c|c|}
\hline \multirow[b]{2}{*}{ Fixed effects } & \multicolumn{3}{|c|}{ Model 2* } & \multicolumn{3}{|c|}{ Model 3† } \\
\hline & Coefficient & $95 \% \mathrm{Cl}$ & $P$-value & Coefficient & $95 \% \mathrm{Cl}$ & $P$-value \\
\hline Time & -0.03 & $-0.07,0.01$ & 0.193 & -0.03 & $-0.07,0.01$ & 0.134 \\
\hline \multicolumn{7}{|l|}{ Parent styles } \\
\hline Authoritative & 0.84 & $0.67,1.01$ & $<0.001$ & 0.75 & $0.59,0.92$ & $<0.001$ \\
\hline Authoritarian & 0.74 & $0.56,0.92$ & $<0.001$ & 0.58 & $0.40,0.75$ & $<0.001$ \\
\hline Permissive & 0.02 & $-0.17,0.22$ & 0.813 & 0.09 & $-0.11,0.28$ & 0.385 \\
\hline Disengaged & - & - & - & - & - & - \\
\hline \multicolumn{7}{|l|}{ Parent styles $\times$ time } \\
\hline Authoritative $\times$ time & $-0 \cdot 13$ & $-0.18,-0.09$ & $<0.001$ & $-0 \cdot 13$ & $-0.18,-0.08$ & $<0.001$ \\
\hline Authoritarian $\times$ time & -0.04 & $-0.10,0.01$ & 0.086 & -0.04 & $-0.09,0.01$ & 0.092 \\
\hline Permissive $\times$ time & -0.06 & $-0.11,0.00$ & 0.055 & -0.06 & $-0.11,0.00$ & 0.060 \\
\hline Disengaged $\times$ time & & & & - & - & - \\
\hline \multicolumn{7}{|c|}{ Children in household (including study child) } \\
\hline 1 child & & & & - & - & - \\
\hline 2 children & & & & -0.07 & $-0.22,0.08$ & 0.379 \\
\hline 3 or more children & & & & -0.12 & $-0.28,0.04$ & 0.131 \\
\hline \multicolumn{7}{|l|}{ Mothers birth place } \\
\hline Australia & & & & - & - & - \\
\hline Not Australia & & & & $0 \cdot 10$ & $-0.01,0.22$ & 0.064 \\
\hline \multicolumn{7}{|l|}{ Mother's education } \\
\hline University & & & & - & - & - \\
\hline Trade/certificate & & & & -0.58 & $-0.69,-0.46$ & $<0.001$ \\
\hline Year 12 & & & & -0.66 & $-0.80,-0.52$ & $<0.001$ \\
\hline Less than year 12 & & & & -1.09 & $-1 \cdot 22,-0.95$ & $<0.001$ \\
\hline \multicolumn{7}{|l|}{ Father in the home } \\
\hline No & & & & - & - & - \\
\hline Yes & & & & 0.27 & $0.13,0.42$ & $<0.001$ \\
\hline \multicolumn{7}{|l|}{ Child's sex } \\
\hline Male & & & & - & - & - \\
\hline Female & & & & 0.23 & $0.14,0.32$ & $<0.001$ \\
\hline Mother's age & & & & 0.02 & $0.01,0.03$ & $<0.001$ \\
\hline \multicolumn{7}{|l|}{ Random effects } \\
\hline Variance (diet quality score) & 0.12 & $0 \cdot 10,0 \cdot 13$ & & $0 \cdot 12$ & $0 \cdot 10,0 \cdot 13$ & \\
\hline & $2 \cdot 34$ & $2 \cdot 17,2 \cdot 51$ & & $2 \cdot 14$ & $1.99,2.31$ & \\
\hline Individual & -0.24 & $-0.28,-0.20$ & & $-0 \cdot 24$ & $-0.28,-0.20$ & \\
\hline Residual & $2 \cdot 78$ & $2 \cdot 72,2 \cdot 85$ & & 2.78 & $2 \cdot 72,2 \cdot 85$ & \\
\hline
\end{tabular}

*A multilevel linear regression model, with both a random intercept and random slope for time, and an interaction between maternal parenting style and time included. †A multilevel linear regression model, with both a random intercept and random slope for time, an interaction between maternal parenting style and time, and potential confounding variables included.

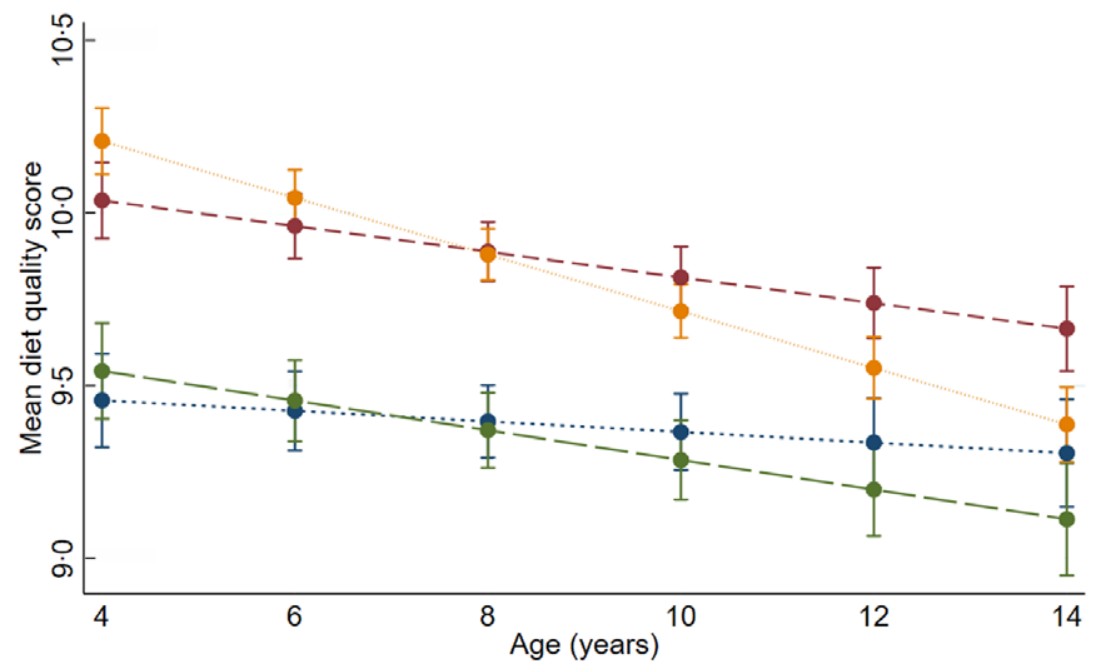

Fig. 2 (colour online) Change in dietary score over time by parenting style from fully adjusted multilevel model of the association between parenting styles and child diet quality score 
but had the greatest decline in diet quality score following the transition to adolescence. Previous cross-sectional studies have shown the authoritative parenting style to be associated with healthier child dietary intake ${ }^{(11,25,26,28-30,53)}$. However, the longitudinal findings presented here add important depth to this field by showing that, although authoritative parenting of young children was associated with the highest diet quality score at the age of 4 years, this was not the case by the age of 14 years. Nevertheless, findings presented in Fig. 2 suggest that although they had the greatest decline in diet quality score, on average, children with authoritative mothers had a better diet quality score than children with disengaged and permissive mothers across the study period. Future interventions should focus on providing support for all parents to improve their child's dietary quality over time and avoid the age-related decline seen in children in the current and previous studies ${ }^{(17,50-52)}$. Support would be particularly important for permissive, disengaged and even authoritative parents to adopt and maintain parenting behaviours that support long-term dietary quality for their children. Interventions should provide support at the important stage of early childhood, when it is thought that a mother has the strongest influence over her child's dietary intake ${ }^{(13-16)}$; however, public health interventions would benefit from longer time frames to ensure sustained benefits ${ }^{(54)}$. For example, providing specific support to promote healthy eating behaviours for their children to different groups of parenting styles as the child grows could be a consideration for future interventions.

Children of authoritative mothers had the greatest decline in diet quality score followed by children of permissive mothers. This suggests that the key dimension for a decline in diet quality score over childhood could be higher levels of maternal warmth, as high levels of warmth are defining characteristics of both permissive and authoritative parenting styles. Parents with high levels of warmth offer nurturance, open parent-child communication and may even adjust their parenting behaviour according to their child's point of view ${ }^{(55)}$. Therefore, it is possible that the warmth dimension may create a highly responsive environment in the home where children are able to indulge in unhealthy foods ${ }^{(56)}$. This is a new finding in the literature and warrants further research using measures that allow for further variability in the responses to allow for the nuances of parenting to be explored ${ }^{(57)}$.

A major strength of the present study was the use of a longitudinal nationwide dataset. Thus, findings may be broadly generalisable to a wider Australian population and temporal ordering in exposure-outcome relationships was able to be assessed, as well as the possibility of examining change over time. The use of a diet quality score capturing multiple food groups was also a strength, as many previous studies have only used single food items $^{(11,25,28-30,53)}$. This is important as consumption of any food does not happen in isolation but as part of a whole dietary pattern ${ }^{(32)}$. While the use of a diet quality score is novel and important, limitations of the dietary questions used to derive the scores include their lack of prior validation, the limited response categories assessing only intake frequency, the use of the same response categories for both healthy and unhealthy foods, the limited number of foods considered, and the assessment of only a single day of food intake, which may have limited the estimates of the child's dietary intake and therefore dietary quality. While assessing frequency from the previous $24 \mathrm{~h}$ may not be completely representative of a child's regular dietary intake, including the dietary intake data from multiple time points (up to six waves) is likely to reduce the error associated with this issue ${ }^{(36)}$. However, future research should focus on a more comprehensive diet quality measure.

A further consideration is that the parenting styles were derived according to the sample distribution of the parenting dimensions rather than to set cut points. While this was consistent with previous literature ${ }^{(11,26,42,44)}$, the positive skew of the parenting dimension scores affects classification of parenting styles. For example, parents who scored $<4.4$ out of 5 on warmth were classified as 'low warmth', which is relative to others in the sample rather than an absolute classification. However, the cut points (tertiles) used in previous studies are not reported for comparison ${ }^{(11,26,42,44)}$.

Additionally, some factors that may influence parental feeding were not taken into consideration in the LSAC and hence in the present study. Of particular importance are feeding practices that can influence children's food consumption, such as parental modelling of eating healthy food and structured meal timing ${ }^{(58)}$. Future research might also examine how parenting styles change over time and how this in turn impacts child diets, as parenting styles are assumed to be stable ${ }^{(20)}$, with one study showing that they are stable throughout adolescence ${ }^{(21)}$. Conversely, just under half of the mothers in the current study had the same parenting style at 4 and 14 years of age. However, results were similar when including children of mothers who changed parenting styles as when only considering children of mothers who had the same parenting style at 4 and 14 years of age. Additionally, the measured confounders such as family structures may have changed since measurement at baseline. Furthermore, parenting dimensions and styles and health-related behaviours, such as dietary intake, may be considered to have different degrees of social desirability bias, especially when questions are asked in face-to-face interviews. It is possible that mothers in this study may have over- or under-reported both their parenting behaviours and their children's dietary behaviours. The influence of social desirability bias on these and related variables needs to be examined in future research. It is also possible that the change in respondent for the dietary measures may introduce some reporting bias or that children may have difficulty remembering their dietary intake. 


\section{Conclusion}

The present study found that children of mothers who reported an authoritative parenting style at child age of 4 years had a greater dietary quality score at baseline, however, exhibited greater declines in diet quality score over childhood (between 4 and 14 years of age) compared to children reared with other parenting styles at 4 years of age. Future interventions should focus on providing support for parents to avoid a decline in their child's dietary quality, especially for authoritative, permissive and disengaged parents. The current findings question previous assumptions based on cross-sectional studies that early exposure to an authoritative parenting style has lasting positive effects for promoting healthy child food consumption. Future studies could include other factors important in parental feeding, such as feeding practices, which would be important in future nutrition interventions.

\section{Acknowledgements}

Acknowledgements: None. Financial support: Funding for this study was provided from HDR funding support from the School of Exercise and Nutrition Sciences, Faculty of Health, Deakin University. The funder had no role in the design, analysis or writing of this article. Conflict of interest: There are no conflicts of interest. Authorship: All authors contributed to the research design. A.J.B. performed the statistical analysis for the manuscript and drafted the paper. All authors contributed to a critical review of the manuscript during the writing process. All authors approved the final version to be published. Ethics of human subject participation: This study was conducted according to the guidelines laid down in the Declaration of Helsinki and all procedures involving human subjects were approved by the Australian Institute of Family Studies Ethics Committee. Written informed consent was obtained from all subjects.

\section{Supplementary material}

For supplementary material accompanying this paper, visit https://doi.org/10.1017/S1368980021003062

\section{References}

1. Reilly JJ, Methven E, McDowell ZC et al. (2003) Health consequences of obesity. Arch Dis Child 88, 748-752.

2. De Onis M, Blössner M \& Borghi E (2010) Global prevalence and trends of overweight and obesity among preschool children. Am J Clin Nutr 92, 1257-1264.

3. World Health Organization (2016) Facts and Figures on Childhood Obesity 2016. Available at http://www.who.int/ mediacentre/factsheets/fs311/en/ (accessed October 2017).
4. Australian Bureau of Statistics (2012) National Health Survey. Summary of Results 2011-2012. Canberra: Australian Bureau of Statistics.

5. Australian Bureau of Statistics (2015) National Health Survey. First Results 2014-2015. Canberra: Australian Bureau of Statistics.

6. Ogden CL, Carroll MD, Kit BK et al. (2012) Prevalence of obesity and trends in body mass index among us children and adolescents, 1999-2010. JAMA 307, 483-490.

7. Sokol RJ (2000) The chronic disease of childhood obesity: the sleeping giant has awakened. J Pediatr 136, 711.

8. Cali AMG \& Caprio S (2008) Obesity in children and adolescents. J Clin Endocrinol Metab 93, S31-S36.

9. Institute for Health Metrics and Evaluation (2016) Global Burden of Disease Country Profile: Australia 2016. Available at http://www.healthdata.org/australia (accessed November 2016).

10. Biro FM \& Wien M (2010) Childhood obesity and adult morbidities. Am J Clin Nutr 91, 1499S-1505S.

11. Park H \& Walton-Moss B (2012) Parenting style, parenting stress, and children's health-related behaviors. J Dev Behav Pediatr 33, 495-503.

12. Scaglioni S, Salvioni M \& Galimberti C (2008) Influence of parental attitudes in the development of children eating behaviour. Br J Nutr 99, Suppl. 1, S22-S25.

13. Campbell K \& Hesketh K (2007) Strategies which aim to positively impact on weight, physical activity, diet and sedentary behaviours in children from 0 to 5 years. A systematic review of the literature. Obes Rev 8, 327-338.

14. Carnell S, Cooke L, Cheng R et al. (2011) Parental feeding behaviours and motivations. A qualitative study in mothers of UK pre-schoolers. Appetite 57, 665-673.

15. Cooke L, Wardle J, Gibson E et al. (2004) Demographic, familial and trait predictors of fruit and vegetable consumption by pre-school children. Public Health Nutr 7, 295-302.

16. Story M, Neumark-Sztainer D \& French S (2002) Individual and environmental influences on adolescent eating behaviors. J Am Diet Assoc 102, S40-S51.

17. Lytle LA, Seifert S, Greenstein J et al. (2000) How do children's eating patterns and food choices change over time? Results from a cohort study. Am J Health Promot 14, 222-228.

18. Vereecken C, Pedersen TP, Ojala K et al. (2015) Fruit and vegetable consumption trends among adolescents from 2002 to 2010 in 33 countries. Eur J Public Health 25, Suppl. 2, 16-19.

19. National Health and Medical Research Council (2013) Eat for Health: Australian Dietary Guidelines Summary. Canberra: National Health and Medical Research Council, Department of Health and Ageing.

20. Darling N \& Steinberg L (1993) Parenting style as context: an integrative model. Psychol Bull 113, 487.

21. Zhang W, Wei X, Ji L et al. (2017) Reconsidering parenting in Chinese culture: subtypes, stability, and change of maternal parenting style during early adolescence.J Youth Adolesc 46, 1117-1136.

22. Baumrind D (1966) Effects of authoritative parental control on child behavior. Child Dev 37, 887-907.

23. Vollmer RL \& Mobley AR (2013) Parenting styles, feeding styles, and their influence on child obesogenic behaviors and body weight. A review. Appetite 71, 232-241.

24. Maccoby EE \& Martin JA (1983) Socialization in the context of the family: parent-child interaction. In Handbook of Child Psychology: Formerly Carmichael's Manual of Child Psychology, pp. 1-101 [PH Mussen, editor]. New York: Wiley.

25. Peters J, Dollman J, Petkov J et al. (2013) Associations between parenting styles and nutrition knowledge and 2-5-year-old children's fruit, vegetable and non-core food consumption. Public Health Nutr 16, 1979-1987. 
26. Burnett AJ, Worsley A, Lacy KE et al. (2019) Moderation of associations between maternal parenting styles and Australian pre-school children's dietary intake by family structure and mother's employment status. Public Health Nutr 22, 997-1009.

27. Burnett AJ, Lamb KE, McCann J et al. (2020) Parenting styles and the dietary intake of pre-school children: a systematic review. Psychol Health 35, 1-20.

28. Kremers SPJ, Brug J, de Vries H et al. (2003) Parenting style and adolescent fruit consumption. Appetite 41, 43-50.

29. Lytle LA, Varnell S, Murray DM et al. (2003) Predicting adolescents' intake of fruits and vegetables. J Nutr Educ Behav 35, 170-178.

30. Pearson N, Atkin AJ, Biddle SJ et al. (2010) Parenting styles, family structure and adolescent dietary behaviour. Public Health Nutr 13, 1245-1253.

31. Lopez NV, Schembre S, Belcher BR et al. (2018) Parenting styles, food-related parenting practices, and children's healthy eating: a meditation analysis to examine relationships between parenting and child diet. Appetite 128, 205-213.

32. Kant AK (1996) Indexes of overall diet quality: a review. J Am Diet Assoc 96, 785-791.

33. Fallaize R, Livingstone K, Celis-Morales C et al. (2018) Association between diet-quality scores, adiposity, total cholesterol and markers of nutritional status in European adults: findings from the Food4Me study. Nutrients 10, 49

34. Soloff C, Lawrence D \& Johnstone R (2005) LSAC Technical Paper No. 1: Sample Design. Melbourne, Australia: Australian Institute of Family Studies.

35. Sallis JF, Taylor WC, Dowda M et al. (2002) Correlates of vigorous physical activity for children in grades 1 through 12: comparing parent-reported and objectively measured physical activity. Pediatr Exerc Sci 14, 30-44.

36. Gasser CE, Kerr JA, Mensah FK et al. (2017) Stability and change in dietary scores and patterns across six waves of the longitudinal study of Australian children. Br J Nutr 117, 1137-1150.

37. National Health and Medical Research Council (2013) Australian Dietary Guidelines. Canberra: National Health and Medical Research Council.

38. Wilson AM, Magarey AM \& Mastersson N (2008) Reliability and relative validity of a child nutrition questionnaire to simultaneously assess dietary patterns associated with positive energy balance and food behaviours, attitudes, knowledge and environments associated with healthy eating. Int J Behav Nutr Phys Act 5, 5.

39. Thornton M \& Williams J (2016) Infant Cohort: Report on the Pilot Phase of Wave Three, Infant Cohort (at 5 Years of Age). Dublin, Ireland: Department of Children and Youth Affairs.

40. Paterson G \& Sanson A (1999) The association of behavioural adjustment to temperament, parenting and family characteristics among 5-year-old children. Soc Dev 8, 293-309.

41. Statistics Canada (1995) National Longitudinal Survey of Children: Survey Instruments for 1994-1995 Data Collection-Cycle 1. Catalogue Number 95-01. Ottawa, Canada: Statistics Canada.

42. Alsharairi NA \& Somerset SM (2015) Associations between parenting styles and children's fruit and vegetable intake. Ecol Food Nutr 54, 93-113.
43. Zubrick SR, Smith GJ, Nicholson JM et al. (2007) Parenting and Families in Australia. Canberra, Australia: Australian Government, Department of Family, Community Services and Indigenous Affairs.

44. Wake M, Nicholson JM, Hardy P et al. (2007) Preschooler obesity and parenting styles of mothers and fathers: Australian national population study. Pediatrics 120, e1520-e1527.

45. Boots SB, Tiggemann M, Corsini N et al. (2015) Managing young children's snack food intake. The role of parenting style and feeding strategies. Appetite 92, 94-101.

46. McPhie S, Skouteris H, Fuller-Tyszkiewicz M et al. (2012) Maternal predictors of preschool child-eating behaviours, food intake and body mass index: a prospective study. Early Child Dev Care 182, 999-1014.

47. Cameron A, Ball K, Pearson N et al. (2012) Socioeconomic variation in diet and activity-related behaviours of Australian children and adolescents aged $2-16$ years. Pediatr Obes 7, 329-342.

48. Stata Corp. (2017) Stata Statistical Software. College Station, TX: Stata Corp., LP.

49. Kwok O-M, Underhill AT, Berry JW et al. (2008) Analyzing longitudinal data with multilevel models: an example with individuals living with lower extremity intra-articular fractures. Rehabil Psychol 53, 370.

50. Marks J, Barnett LM \& Allender S (2015) Change of school in early adolescence and adverse obesity-related dietary behavior: a longitudinal cohort study, Victoria, Australia, 2013-2014. Prev Chronic Dis 12, E145.

51. Albani V, Butler LT, Traill WB et al. (2017) Fruit and vegetable intake: change with age across childhood and adolescence. Br J Nutr 117, 759-765.

52. Jongenelis MI, Scully M, Morley B et al. (2018) Vegetable and fruit intake in Australian adolescents: trends over time and perceptions of consumption. Appetite 129, 49-54.

53. Langer SL, Seburg E, JaKa MM et al. (2017) Predicting dietary intake among children classified as overweight or at risk for overweight: independent and interactive effects of parenting practices and styles. Appetite 110, 72-79.

54. Hesketh KD, Salmon J, McNaughton SA et al. (2020) Longterm outcomes (2 and 3.5 years post-intervention) of the INFANT early childhood intervention to improve health behaviors and reduce obesity: cluster randomised controlled trial follow-up. Int J Behav Nutr Phys Act 17, 1-10.

55. Coplan RJ, Hastings PD, Lagacé-Séguin DG et al. (2002) Authoritative and authoritarian mothers' parenting goals, attributions, and emotions across different childrearing contexts. Parenting 2, 1-26.

56. Berge JM, Wall M, Loth $\mathrm{K}$ et al. (2010) Parenting style as a predictor of adolescent weight and weight-related behaviors. $J$ Adolesc Health 46, 331-338.

57. Phillipson S, McFarland L \& Studies F (2016) Australian parenting and adolescent boys' and girls' academic performance and mastery: the mediating effect of perceptions of parenting and sense of school membership. J Child Fam Stud 25, 2021-2033.

58. Jansen E, Williams KE, Mallan KM et al. (2016) The feeding practices and structure questionnaire (FPSQ-28): a parsimonious version validated for longitudinal use from 2 to 5 years. Appetite 100, 172-180. 